\title{
INTRACARDIAC TUMOURS
}

\author{
BY

\section{J. L. HAMILTON-PATERSON AND L. I. M. CASTLEDEN} \\ From the Redhill County Hospital, Edgware, Middlesex
}

Received June 1, 1942

Three cases of intracardiac tumour are reported in this paper and are of interest, apart from the comparative rarity of the condition, because in each case the clinical signs and symptoms suggested the presence of another lesion and the tumour was only discovered post-mortem.

The first case, with a round-cell and spindle-cell sarcoma of the right auricle, showed in life the signs and symptoms of Ayerza's syndrome. The second, with a pedunculated myxomatous tumour of the left auricle, which projected through the mitral valve, was diagnosed as mitral stenosis. The third, with a tumour only in the sense that it was an intracardiac swelling, had a mycotic aneurysm arising at the attachment of the anterior cusp of the aortic valve, extending downwards into the interventricular septum and bulging into the right ventricle; the aortic valve was the seat of a bacterial endocarditis: in life the bulging into the right ventricle had obstructed the pulmonary valve, and a diagnosis of pulmonary stenosis and rheumatic carditis had been made.

\section{Sarcoma of Right Auricle}

Case 1. A woman, aged 45 years, was admitted 30/7/41 complaining of increasing shortness of breath on exertion, of blueness of the lips for five months, and of a cough with scanty sputum for the past four weeks. Her doctor stated that auricular fibrillation had developed within the last week. She had always been strong and healthy except for a tendency to winter cough for the past five or six years. No history of rheumatic fever or chorea.

On examination she was an obese woman with intense plum-coloured cyanosis but without dyspnœa at rest. The heart appeared normal in size. Auricular fibrillation at 84 a minute was present. There were no murmurs. The blood pressure was $120 / 80$. The lungs were emphysematous without any added sounds. The cervical veins were not overfilled, and there was no œdema of the subcutaneous tissues and no enlargement of the liver or spleen. The appearance of the patient suggested polycythæmia, but her blood count showed 4.7 million red blood corpuscules and 94 per cent hæmoglolin, with a colour index of $1 \cdot 0$. The urine was normal except for a trace of albumin. An electrocardiogram confirmed the presence of auricular fibrillation and showed low voltage of the QRS complexes and a flat $T$ wave in lead III. There was no abnormal axis deviation.

On $6 / 8 / 41$ the right leg suddenly became swollen up to the groin, painful, 103 
œdematous, and more blue than the left. Physical examination showed no other change. The white blood corpuscles were 7000 per c.mm., with neutrophils 73 per cent, lymphocytes 15 per cent, monocytes 10 per cent, and eosinophils 2 per cent. On 11/8/41 there were a few râles at the right base, and thereafter signs of congestive failure increased until on 17/8/41 there were bilateral pleural effusions with œdema of both legs up to the groins. The right leg, which had remained swollen since the onset of the venous thrombosis, was still more œdematous. The heart appeared to be enlarged to the left and fibrillation was still present at 88 a minute. Mersalyl produced a severe reaction and was discontinued. Other efforts to relieve her congestion failed and sacral œdema appeared. On 25/8/41 the heart was still enlarged but the rhythm now became regular, the blood pressure remaining at 120/80. A cardiogram confirmed the presence of regular rhythm at 84 a minute, with a $\mathrm{P}-\mathrm{R}$ interval of $0.28 \mathrm{sec}$. The $\mathrm{QRS}$ complexes still showed a low voltage with normal $\mathrm{R}-\mathrm{T}$ intervals. The $\mathrm{T}$ waves in leads $\mathrm{I}$ and II were upright but flat in lead III.

The patient remained very ill with no change in her congestive failure, and on 30/8/41 venous thrombosis occurred in the right arm, which was œdematous up to the shoulder. Edema of the right breast developed. Acupuncture of both feet was performed; the punctures drained about three pints a day and all the œdema, except that of the right arm, disappeared. The cyanosis, however, which had remained a marked feature throughout, became more intense, and for the first time she began to be dyspnœic at rest in bed. The Wassermann, Kahn, and Laughlen reactions were negative, and an X-ray of her chest showed an abnormal heart shadow with considerable bulging to the right, the appearance being consistent with pulmonary stenosis. The patient was too ill to be screened. Edema now began to increase again, and on 12/10/41 venous thrombosis occurred in the left arm. From this point the patient's condition steadily deteriorated. Slow auricular fibrillation at 90 a minute recommenced, the cervical veins became overfilled and the œdema progressed to a generalized anasarca with intense cyanosis, which persisted until death on 22/11/41.

Post-mortem Examination. Heart weight $600 \mathrm{~g}$. Parietal pericardium normal. There was a blood-stained pericardial effusion of about $4 \mathrm{oz}$. The heart was enlarged and grossly distorted by a lobulated tumour growing in the right auricle. When the right side of the heart was opened the whole auricle was filled with large nodules of growth all arising from the auricular wall which was itself thickened with growth (Fig. 1). The tumour was soft and white in colour, but in places there were large hæmorrhages into it. Auricular cavity, almost completely occluded by growth. Right and left ventricles and left auricle, normal except for some distortion caused by pressure of the enlarged right auricle. Pulmonary artery, normal. One nodule of tumour had grown through the inter-auricular wall and was presenting as a red mass in the left auricle about half an inch in diameter. The right coronary vein appeared to be completely occluded by growth. The superior vena cava was filled with clot, which, on dissection, was found to consist of several clots separately attached to the wall of the vein and joined together by post-mortem thrombus. 


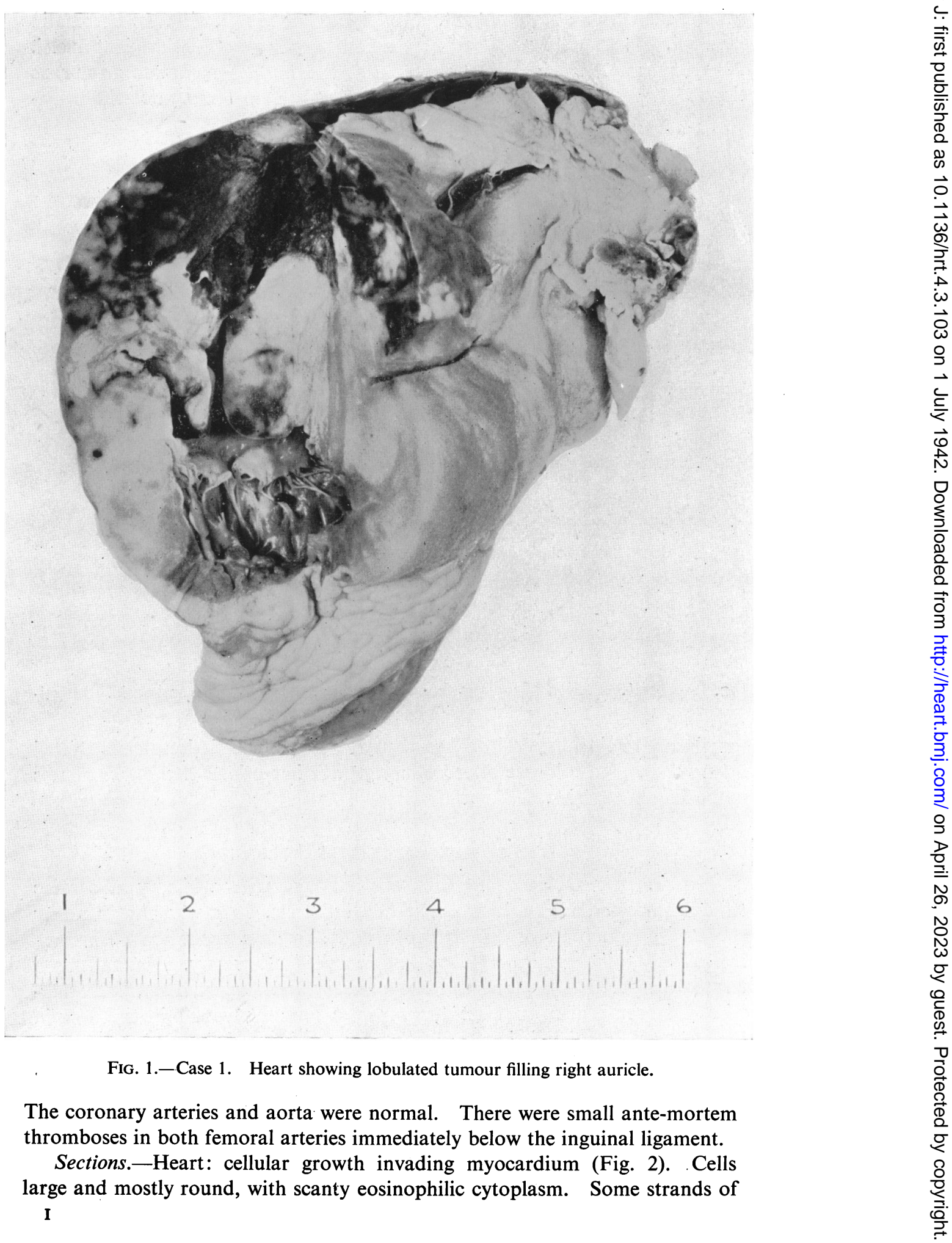


spindle-shaped cells were present. Nuclei, oval or round, with fine chromatin network. There were one or two areas with very large cells with giant nuclei. No true giant cells seen. Sections stained by Van Gieson showed no fibrous tissue. In many sections, stained with Mallory's phosphotungstic acid hæma-

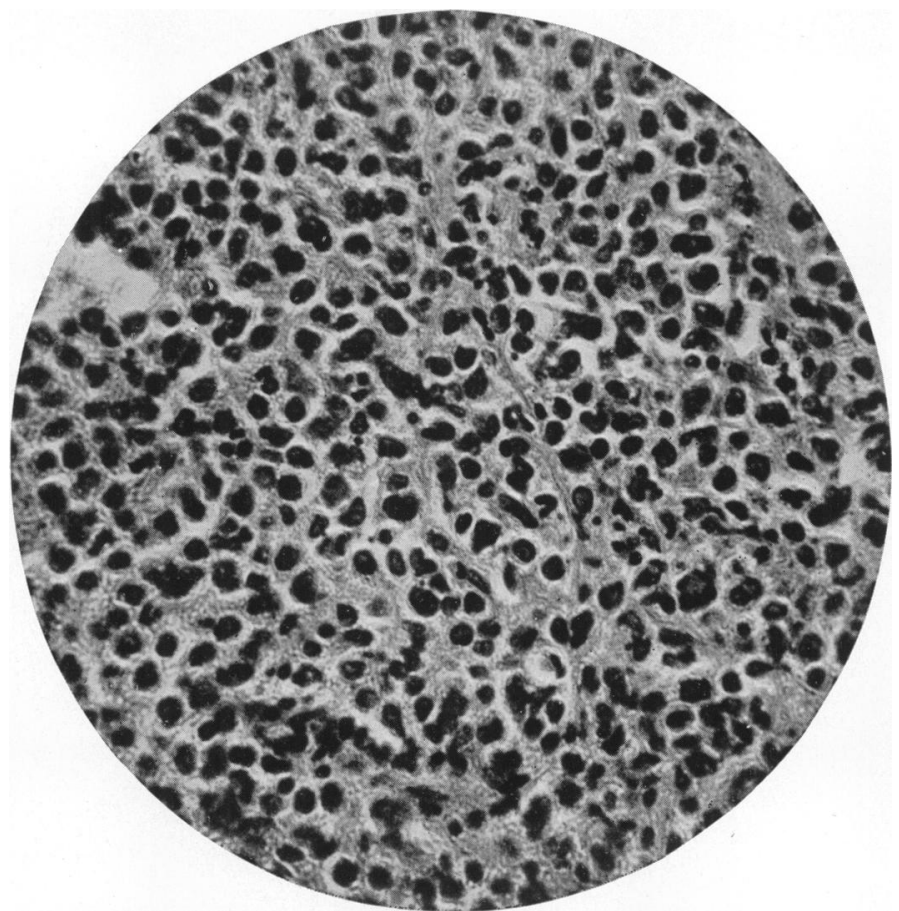

FIG. 2.-Case 1. Section of tumour showing structure. Hæmatoxylin and eosin. Magnification $\times 350$.

toxylin and Heidenhain's iron hæmatoxylin, no cross striation demonstrated in the cells. No evidence of secondary growth in sections of the thromboses in the femoral arteries.

\section{Pseudo-MyXoma of LefT Auricle}

Case 2. A man, aged 46 years, was admitted with a history of cardiac trouble since the age of 15 when he had influenza. He was always rather short of breath but was able to work until ten days ago when he became increasingly weak and breathless and vomited frequently. $\mathrm{He}$ had been treated for gastric symptoms between January and August, 1940, but otherwise had been well in the past apart from a gunshot wound in the neck in the last war. On admission he was extremely blue and dyspnœic with tense neck veins. Cold extremities. No œdema. Pulse 79, weak but regular. Blood pressure not registered (systol.c below 90). Heart: grossly enlarged to left; loud apical systolic murmur. Lungs: congestion of both bases, more marked on the right. Abdomen: liver enlarged, almost to umbilicus, and tender. He died two days after admission.

Post-mortem Examination. Heart weight 750 g., grossly enlarged. Peri- 
cardium and pericardial cavity normal. There was some hypertrophy of the right ventricle, which was filled with post-mortem clot. The tricuspid valve and the pulmonary valve were normal. Left auricle filled with a large pedunculated yellowish mass which had a short process projecting through the mitral valve into the left ventricular cavity. This mass was attached firmly to the middle wall of the left auricle over an area of about an inch in diameter (Fig. 3).

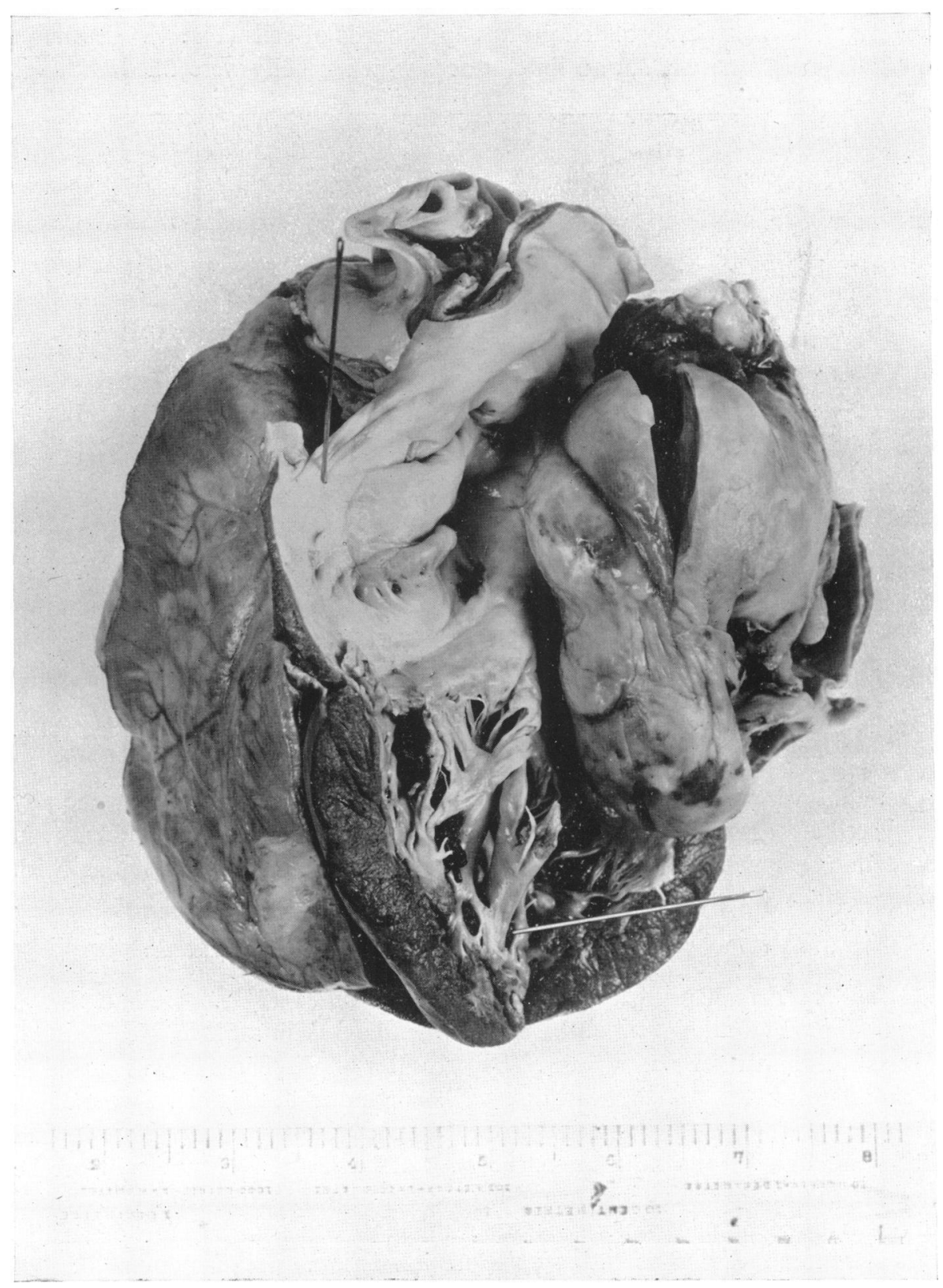

Fig. 3.-Case 2. Heart showing pedunculated tumour in left auricle. 
The mass itself was solid in the lower part, but in the upper part was composed of small attached grape-like structures, which, on section, appeared to be myxomatous. Section of the solid parts showed structure partly laminated, partly hæmorrhagic, and partly amorphous. There was a small process, which was calcified, attached to the part projecting through the mitral valve. The mitral and the aortic valves and the coronary arteries were normal.

Sections.-Composed chiefly of structureless or fibrillary eosinophilic material in which were isolated groups and chords of cells (Fig. 4). In places these cells were flattened, and lined spaces which usually were filled with red

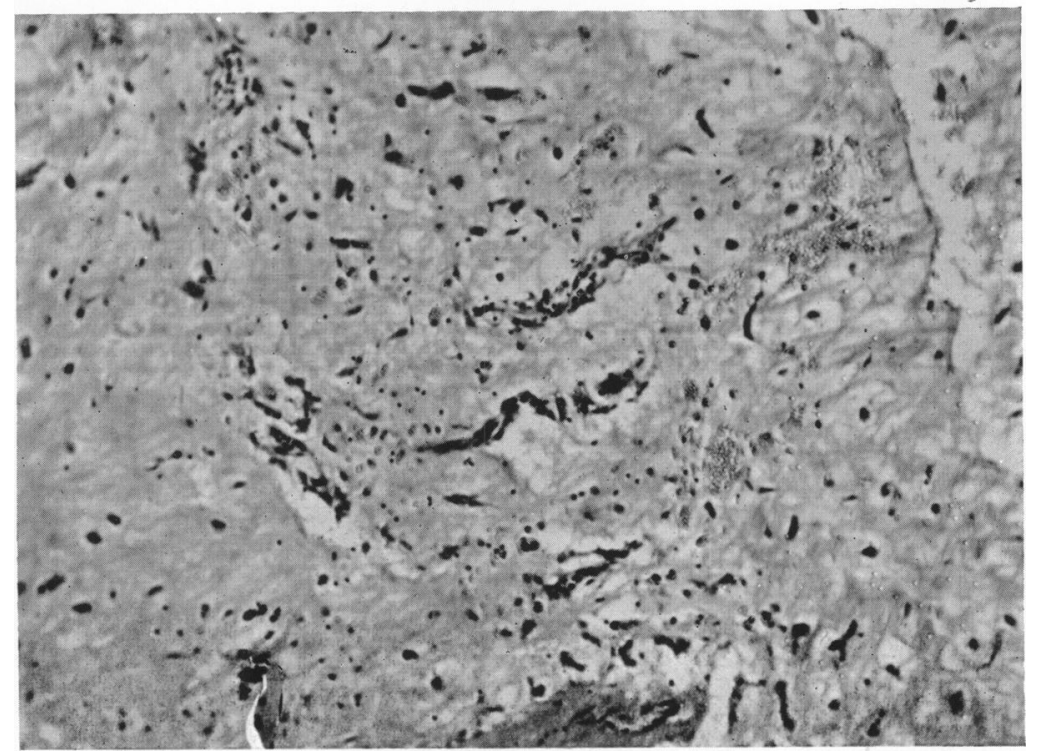

FIG. 4.-Case 2. Section of tumour showing general structure. Hæmatoxylin and eosin. Magnification $\times 120$.

cells. Elsewhere the cells were rounded and had more cytoplasm and generally appeared like swollen connective tissue cells (Fig. 5). There was much iron containing pigment showing a perivascular distribution. Sections stained with thionin showed mucoid degeneration scattered irregularly through the sections.

\section{Mycotic Aneurysm Simulating Pulmonary Stenosis}

Case 3. A man, aged 25 years, was admitted on 31/12/41. He had always been quite well until eight months before when he was in a Shropshire hospital for six weeks with rheumatic fever. Shortly after his discharge he was passed fit for military service, " slight heart disease" being noted at the time. Two months later he was re-examined and said to be "cured." Four months before he had been discharged from the army on account of his heart. Six weeks before he had began to have aching in arm and leg joints without swelling, and was treated at home for rheumatic fever. At the same time he began to be short of breath, this symptom steadily increasing up to his admission. He also complained of thirst and had passed less urine than usual. For three days there had been 


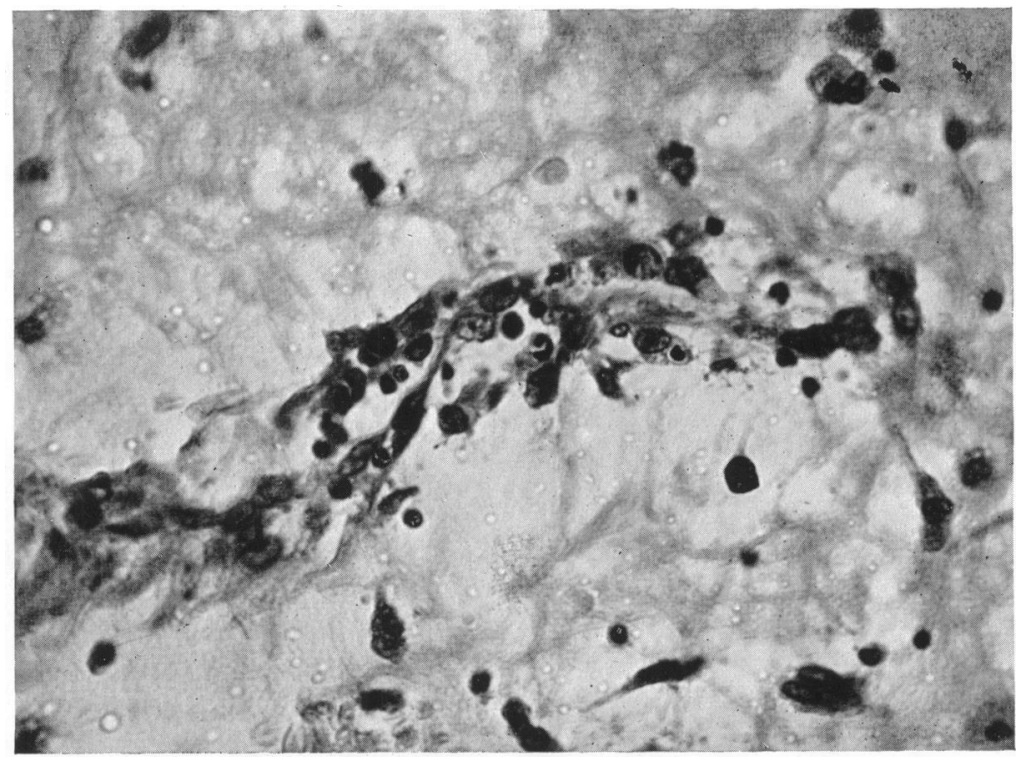

FIG. 5.-Case 2. Showing a cord of swollen connective tissue cells. Hæmatoxylin and eosin. Magnification $\times 350$.

puffiness of his eyelids with slight headache. On admission he was wasted, with clubbing of the fingers, cyanosis, and dyspnœa, but was able to lie flat. There was puffiness of the eyelids, but no other peripheral œdema. The heart was enlarged to the left, the apex beat being almost out to the anterior axillary line in the fifth space, with a regular tachycardia at 138. Systolic and diastolic murmurs were present at both the mitral and aortic areas. There was a loud rough systolic murmur at the pulmonary area, which was conducted upwards and outwards to the left. A thrill was not felt. The blood pressure was 150/90. The lungs were normal. In the abdomen the liver edge was three inches below the costal margin and was smooth and tender. The spleen was just palpable. There was no ascites. No petechiæ were seen. A diagnosis of pulmonary stenosis with super-added infective endocarditis and perhaps rheumatic carditis was made. The patient died a few hours after admission.

Post-mortem Examination. Heart weight 630 g. Pericardium normal, but a pericardial effusion of about 6 oz. of clear yellow fluid. Both ventricles hypertrophied, particularly the left. Myocardium, pale in colour but not friable. Mitral valve, normal in every respect; no change found in the left auricle. Aortic valve, completely disorganized, cusps adherent and calcified with numerous small beady vegetations all over their surfaces. The orifice of the aortic valve was irregular and nowhere more than one-eighth of an inch diameter. The extreme fibrosis and calcification of the aortic valve had caused distortion of the sinus of Valsalva, and the orifices of the coronary arteries were completely pulled out of place. The anterior wall of the aorta, between the origin of the right coronary artery and aortic cusps, was infected and had given way to form a mycotic aneurysm pushing downwards in the interventricular wall. The cusps of the pulmonary valve were stretched over 
the anterior wall of the aneurysm and very much distorted. The aneurysm projected into the right ventricular cavity and gave the appearance of a smooth rounded tumour (Fig. 6). The aorta itself was narrowed, but when it was

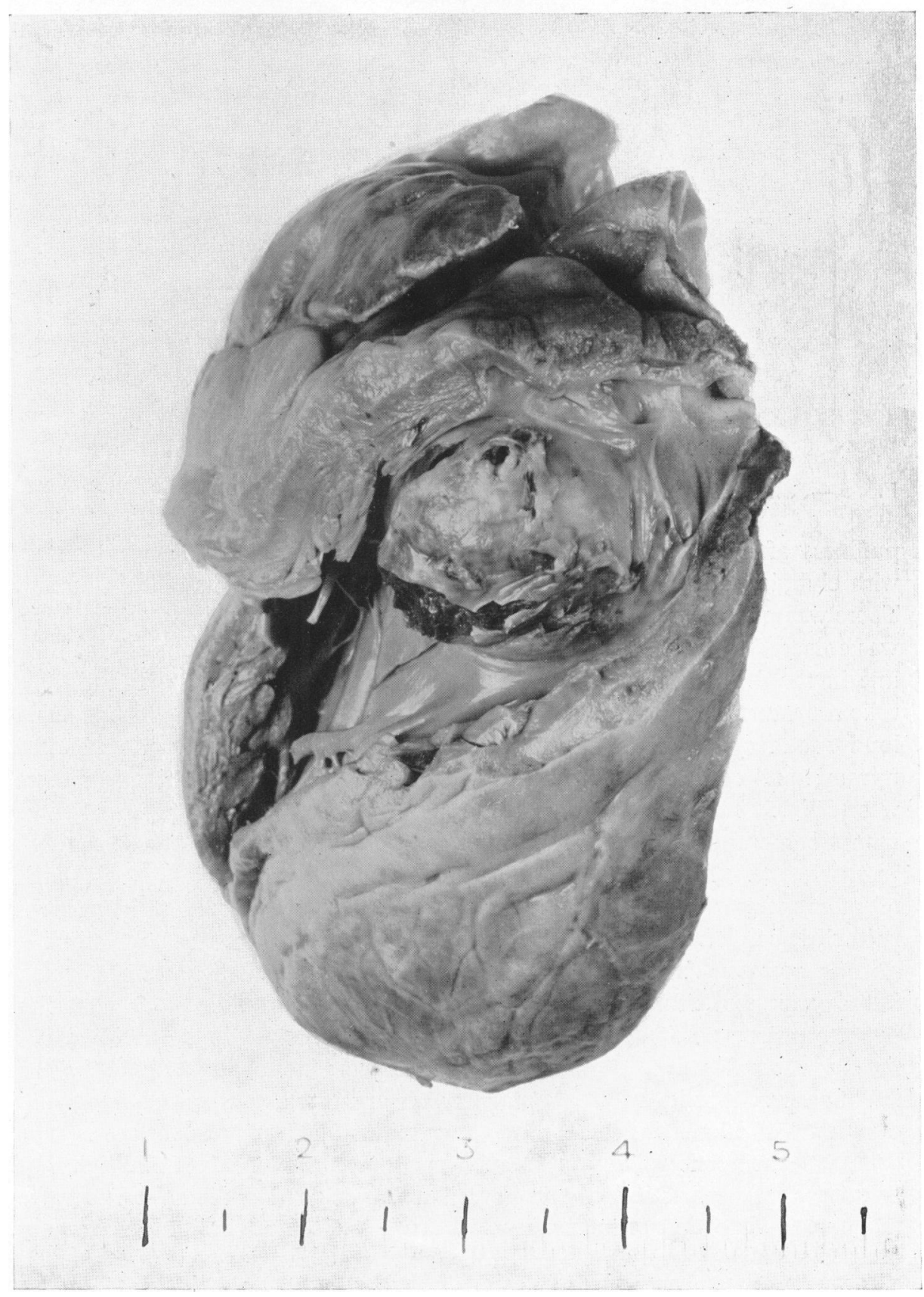

FIG. 6.-Case 3. Showing projection of the aneurysm into the right ventricle with distortion of the cusps of pulmonary valve. 
opened there was no evidence of atherosclerosis. The distortion of the aortic valve was so great that it was impossible to tell whether it was tricuspid or not. The cavity of the aneurysm was lined by a smooth, shining membrane. In the wall of the left ventricle, at the root of the aorta, there was a cavity about one inch long and half an inch in diameter, filled with creamy blood-stained material. This was apparently an abscess in the myocardium extending directly from the infected anterior cusp of the aortic valve. The cavity of the right ventricle, apart from the distortion caused by the aneurysm, showed no abnormality. The tricuspid valve and the right auricle were normal. There was no occlusion of the coronary arteries.

Sections.-The wall of the aneurysm showed organizing and infected blood clot. The myocardium contained many free cells, macrophages, and polymorphs. There were some perivascular collections of macrophages suggesting the formation of Aschoff bodies.

\section{Discussion}

Clinical.-Intracardiac tumour is seldom suspected and less often diagnosed because of the rarity of the lesion and the absence of characteristic signs and symptoms. In adults the commonest findings are those of congestive cardiac failure and cardiac enlargement with or without murmurs suggesting valvular lesions. There may, however, be no signs or symptoms referable to the heart (Bradley and Maxwell, 1928). Other symptoms recorded have been cough, hæmoptysis, weakness, attacks of fainting, præcordial pain, abdominal pain, headache, and vomiting. Edema is usually general, but may be confined to the face, neck, upper arm, and thorax, suggesting occlusion of the superior vena cava. Various pulse abnormalities have been described, and in two cases there was heart block. Pleural and pericardial effusions often occur and may be hæmorrhagic. The malignant tumours may give rise to secondary growths, presumably blood borne, in the lung, pancreas, intestine, etc. (Muller, 1932).

In fact, the presence of a tumour in the walls or cavities of the heart may simulate all kinds of cardiac disease, and such diagnostic criteria as one can formulate must lie in the very multiplicity of the signs. These may be such that they suggest two separate lesions that are unlikely to occur together, and the presence of even one markedly anomalous sign perhaps should lead one to include "tumour" in the differential diagnosis. In children, of course, the natural diagnosis has been congenital morbus cordis (Farber, 1931), but signs of cerebral sclerosis or other congenital abnormality should lead one to suspect rhabdomyoma of the heart, as this occurs in a large percentage of cases of tuberose sclerosis.

Case 3 particularly shows anomalous features. The signs were those of pulmonary stenosis of marked degree with probably old rheumatic lesions of the aortic and mitral valves and an added infective endocarditis. Pulmonary stenosis is usually congenital, but in this case it had not been discovered at his several previous medical examinations and must have developed within two or three months. The changing nature of the signs recorded by the medical board were in favour of the infective nature of the lesion. Although these 
features raised doubts as to the nature of the valvular lesion, further study would probably not have led to an accurate diagnosis of the condition found postmortem. In Case 1 the successive diagnoses had to be discarded for lack of confirmatory evidence. At the first examination she appeared to be a case of primary polycythæmia, but this could not be supported in face of the blood count. No evidence of syphilis could be found to corroborate a diagnosis of Ayerza's disease, and the lungs were comparatively clear. The peripheral thromboses were insufficient to account for the intense cyanosis. Such a degree of cyanosis should have been accompanied by secondary polycythæmia, or by the early appearance of right heart failure with congestion, or both. However, none of these conditions obtained until the patient was moribund. Had the patient been well enough to have been screened, the gross enlargement of the right auricle might have been demonstrated, and this, in conjunction with the physical signs, might have led to a correct diagnosis. In Case 2, the clinical appearances were those of a single rheumatic lesion of the mitral valve without a definite history of rheumatism. This does occur in both sexes of course, but is more common in females. A similar tumour, arising from the aortic valve and causing sudden death was described by Campbell and Carling (1934).

Pathological.-The chief interest lies in the pseudo-myxoma described in the second case. Nearly 200 primary heart tumours have been described and about half of these fall into the pseudo-myxoma group. The study of their histological features has resulted in two theories relating to their origin. Thorel (1903) and, more recently, Fawcett and Ward (1939) thought they were pedunculated thrombi, which, during the process of organization, underwent a mucoid degeneration that gave rise to their myxomatous appearance. Other observers contend that the tumours are primarily new growths, and each has given them names according to their variations in structure. Thus Rau (1898), Manifold (1915), and Schuster (1914) described cavernous angiomata; Hornowski (1906) and Orr (1942) described endotheliomata; Lloyd (1929) and Armstrong and Monckeburg (1911) described lymphangio-endotheliomata; Fabris (1923) described a fibro-angio-myxoma, and Brenner (1907) a hæmangio-elastomyxoma. The basic histological structure tends to be constant in all these tumours, and difference of opinion as to their ætiology has arisen from different interpretations of the observed features. The various elements may be present in different proportions giving rise to rather widely varying pictures, but in all cases the matrix of the tumour is the structureless pseudo-myxomatous material. In this are spaces lined by endothelium, which may be large enough to resemble sinuses or as small as capillaries, and all intermediate stages are met with. If the sinus-like spaces predominate, the appearance of angioma is simulated. If instead of spaces, the cells are in rows or columns the appearance is that of an endothelioma. In our case these columns rarely contained more than two rows of cells and looked like strands of young connective tissue growing into the stroma. Scattered throughout the sections, often ranged perivascularly, are areas showing large or small masses of iron containing pigment.

Most observers are agreed that the mucoid tissue is the result of degeneration, but the presence of mucin has been said to denote the epithelial origin of 
a tumour, although in these cases the only possible source of mucin would be the lining cells of the vascular spaces; perivascular distribution of the mucin in some of the tumours has been cited in favour of this. The presence of iron is said by some to be due to the breaking down of blood in the thrombus and by others to have resulted from hæmorrhage into the tumour, particularly in the angiomatous types. Elastic fibres have also been described and put forward as evidence of new growth, but Muller (1932) points out that they may occur in well-organized thrombi. The cellular elements have been regarded as neoplastic because in some cases they appear to reproduce differentiated structures such as blood and lymph sinuses, and sometimes appear hyperplastic, i.e. they may be swollen and contain one or two nuclei or may be built up into two or more layers. All these appearances, however, may be met with when young connective tissue cells invade blood clot during the process of organization. We have recently seen a case of mitral stenosis that showed a large plaque-like mass of organizing thrombus adherent to the medial wall of the left auricle, which histologically showed all the above features except that elastic tissue was absent. It would seem, therefore, that organizing thrombus can produce the picture called pseudo-myxoma, and in the absence of definite features, which could be ascribed only to a neoplasm, i.e. the presence of tumour tissue in the heart wall itself, it is reasonable to suppose that they are organizing thrombi.

These tumours usually occur in the left auricle and are often attached in the region of the scar of the foramen ovale. Meroz (1917) collected 40 reports of primary intracardiac tumour, 30 of which were in the left auricle. The surface of the tumours may either be smooth, as in our case, or have a granular appearance. On section the cut surface looks translucent and mucoid, and the outer layers may be composed of laminated blood clot.

Case 1 is a true sarcoma, composed of round and spindle cells. Bradley and Maxwell (1928) have classified 36 cases of primary sarcoma of the heart; 12 were spindle-cell, 10 round-cell, 4 giant-cell growths, 3 myxosarcomatous, and 1 each lymphosarcomatous and angiosarcomatous. These tumours are known to metastasize as in two cases reported by Muller (1932), one with a secondary nodule in the lung, and the other with secondary nodules in the lung, pancreas, and small intestine. This latter case and the case first reported by Bradley and Maxwell (1928) were examples of rhabdomyosarcomata with demonstrable cross striation in some of the tumour cells.

There is yet a third main group of intracardiac tumours, the congenital rhabdomyomata. These are composed of cells similar to embryonic heart muscle (" spider cells"), are often associated with tuberose sclerosis; they are never malignant and often multiple.

From our survey of the reported cases, it would appear that all the cases can be placed into one of the three main groups discussed: i.e.:-

(1) the pseudomyxomata, which for reasons already explained are probably not true tumours but organized thrombi,

(2) the true sarcomata, which may arise from any of the mesenchymal elements in the heart wall, and 
(3) the congenital rhabdomyomata (dysontogenetic rhabdomyoma, hamartoma).

The pseudomyxomata form the largest group and comprise nearly half of the tumours described. One quarter of the cases fall into the class of primary sarcoma. Beck and Thatcher (1925) commented on thirty-three reported cases and added one of their own. Nowicki (1926) reported four cases, Matras (1927) one case, and Bradley and Maxwell (1928) and Muller (1932) added one and two cases respectively. The remaining 25 per cent of the cases belong to the category of congenital rhabdomyoma. Farber (1931) found forty-one cases reported, and since then we have only come across two more cases, one described by Ill and Gray (1941) and one by Stewart (1939).

\section{SUMMARY}

Three cases of intracardiac tumour are described, a sarcoma, a " pseudomyxoma," and an aneurysm; which in life produced signs and symptoms attributable to Ayerza's syndrome, mitral stenosis, and pulmonary stenosis respectively.

The origin of pseudomyxomata of the heart is discussed. It is suggested that they are not primarily neoplastic but are pedunculated thrombi as all their histological features may be reproduced in organizing blood clots.

A classification of heart tumours is suggested:

(1) Benign tumours resulting from organization of blood clotpseudomyxomata,

(2) Malignant tumours arising from any of the mesenchymal elements of the heart wall, the true sarcomata, and

(3) Benign congenital tumours arising from developing myocardial elements, the congenital rhabdomyomata (dysontogenetic rhabdomyoma, hamartoma).

Dr. G. H. Jennings kindly gave us permission to publish the clinical details of Case 2. The photographs were taken by Mr. H. D. J. Cole.

\section{REFERENCES}

Armstrong, H., and Monckeburg, J. G. (1911). Dtsch. Arch. klin. Med., 102, 144.

Beck, C. S., and Thatcher, H. S. (1925). Arch. intern. Med., 36, 830.

Bradley, E. B., and Maxwell, F. S. (1928). J. Amer. med. Ass., 91, 1352.

Brenner, F. (1907). Frankf. Z. Path., 1, 492.

Campbell, M., and Carling, W. R. (1934). Guy's Hospital Reports, 84, 41.

Fabris, A. (1923). Arch. Path. Anat., 241, 59.

Farber, S. (1931). Amer. J. Path., 7, 105.

Fawcett, R. E. M., and Ward, E. M. (1939). Brit. Heart J., 1, 249.

Hornowski, J. (1906). Zbl. Allg. Path., 17, 773.

Ill, C. H., and Gray, J. W. (1934). Amer. J. Obstet. Gynaetc., 28, 265.

Lloyd, P. C. (1929). Bull. Johns Hopkins Hosp., 44, 149.

Manifold, R. F. (1915). Lancet, 2, 1027.

Matras, A. (1927). Z. H. Kreisslaufforsch., 19, 233

Meroz, E. (1917). Internat. Clin., 4, 231.

Muller, W. (1932). Virchow's Arch., 284, 105.

Nowicki, W. (1926). Virchow's Arch., 259, 502.

Orr, J. W. (1942). J. Path. Bact., 54, 125.

Rau, F. (1898). Arch. Path. Anat., 153, 22.

Schuster, H. (1914). Arch. Path. Anat., 215, 335.

Stewart, T. D. (1939). N. Zealand med. J., 38, 19.

Thorel, C. (1903). Ergebn. Allg. Path., 91, 901. 